\title{
Timeless evolution of walking and pace strategy of women's race walking
}

\author{
Panagiot $\alpha$ Fitili ${ }^{\mathrm{ABCDE}}$, Vasilios Giovanis ${ }^{\mathrm{ABCDE}}$ \\ National and Kapodistrian University of Athens, Greece
}

Authors' Contribution: A - Study design; B - Data collection; C - Statistical analysis; D - Manuscript Preparation; E - Funds Collection.

\begin{tabular}{|c|c|}
\hline \multicolumn{2}{|l|}{ Abstract } \\
\hline Purpose: & $\begin{array}{l}\text { The purpose of this research was to study the timeline evolution of walking, as well as the Pacing Strategy } \\
\text { Profiles of high-level women in the } 20 \mathrm{~km} \text { of race walking. }\end{array}$ \\
\hline Material: & $\begin{array}{l}\text { The practical example of applying the theoretical basis was made during the Women's Greek } \\
\text { Championship (Megara 2016), in which } 12 \text { athletes aged } 19 \text { to } 40 \text { participated ( } 28.50 \pm 7.20) \text {. The certified } \\
\text { distance of the } 20 \mathrm{~km} \text { route was divided into } 10 \text { sections of } 2 \mathrm{~km} \text { each. The same happened with the } \\
\text { times (intermediate, final) corresponding to the individual sections }(2 \mathrm{~km}) \text { of the route. The athletes were } \\
\text { divided into } 4 \text { groups: the first } 3 \text {, those who finished } 15 \% \text { slower than the first, those who finished } 15 \% \text { - } \\
30 \% \text { slower, and those who finished more than } 30 \% \text { slower than the winner. Finally became comparison } \\
\text { of the first } 6 \text { and last } 6 \text { athletes' groups. }\end{array}$ \\
\hline Results: & $\begin{array}{l}\text { The individual pace strategies that describe the tactics of the athletes in this race have been calculated. } \\
\text { It was found that the winners of the race used Even Pacing Strategy, maintaining a steady speed on most } \\
\text { of the route. As the level of women athletes became lower, Variable Pacing Strategy was used, while the } \\
\text { athletes who finished last did not seem to be able to maintain any particular pacing strategy. }\end{array}$ \\
\hline Conclusions: & $\begin{array}{l}\text { It is suggested that athletes should follow Even Pacing Strategy during the race in order to improve their } \\
\text { performance. }\end{array}$ \\
\hline Keywords: & race walking, even pacing strategy, variable pacing strategy, performance. \\
\hline
\end{tabular}

\section{Introduction}

Various activities that are repeated on a daily basis put the human body on a motor alert, whether it is for social, working or sporting purposes. Beginning of walking from stillness is considered to be one of the most common activities of a person in its daily living. Depending on the purpose and the method, we can divide it as follows:

1) Simple walk or walk is considered as the natural way of moving the human body into space from its infancy [1].

2) The healing walk, which is the acceptance of exercise as a practical form of rehabilitation, promotion and preservation of health, as it was known by Byzantine medicine [2].

3) Recreational walk or walk as a recreation. Mannel \& Reid, [3] and Sylvester, [4] define three dimensions based on: (a) Leisure as free time, (b) Leisure as an experience, (c) Leisure as an activity. It is therefore understood, that recreation is a broader concept that involves active activity, whereas entertainment involves passive activity [5].

4) Nordic walking is walking with specially designed walking sticks, to improve fitness [6].

5) Race walking is a part of the classical athletics and one of the Olympic Games, in which athletes move as fast as possible without running in routes of $20 \mathrm{~km}$ and $50 \mathrm{~km}$.

The great schools of race walking were created after the war. First the Soviet School, later the Italian, the Spain, the Mexican, the Poland, the German and last the Chinese.

(c) Panagiota Fitili, Vasilios Giovanis, 2020

doi:10.15561/26649837.2020.0601
The most important athlete of race walking was the Polish Robert Korzeniowski. He has had gain four gold Olympic medals ( 3 in $50 \mathrm{~km}$ and 1 in $20 \mathrm{~km}$ ), and four medals in World Championships ( 3 gold and 1 bronze, all in $50 \mathrm{~km}$ ).

The basic rules of race walking:

Race walking is carried out on flat public roads. Athletes walk $20 \mathrm{~km}$, repeating 10 times routes of $2 \mathrm{~km}$, or 4 times routes of $5 \mathrm{~km}$. There are rules that differentiate walking from running and athletes of race walking have to know them and follow them. According to Regulations, article 230 IAAF Track and Field Regulations 2012-13 "Race walking is a sequence of steps. The race walker contacts the ground in a way that, no visible (in the human eye) loss occurs.

The forward leg should be stretched (not bent at the knee) from the point of first contact with the ground to the vertical upright position". Judges of race walking watch the athletes during the race and exclude them, if their foot is not stretched on the ground or, if they both lose contact with it. When the judge finds an infringement, he makes his first remark. If the offense is repeated, then the athlete's warning exclusion is placed on a sign visible to all participants in the race. If three different judges charge the athlete in violation, then exclusion follows.

Pace strategy in race walking

The observation that athletes' speed during a race varies caused interest as far as the pace strategy they should follow is concerning. This strategy is a key factor in the success of athletes in sports events [7]. Pace strategy is the ability to regulate the speed of an athlete's movement in order to reach the end of the race in a shorter 
time $[8,9]$. The tempo or pace strategy relates to racing: (a) up to $40 \mathrm{sec}$ (sprint), (b)from $40 \mathrm{sec}$ up to a few minutes (short distance), (c) medium and long distance and overtime, which last for hours [10]. Aschenbrenner, Erdmann, Giovanis, \& Lipinska, [11] had investigated the tactics and technique of race walking at the 2004 Athens Olympics. Ruchlewicz et al., [12] studied the tactic of race walking, based on measurements made in athletes on a floor meter. It is well known that athletes should not run at high speed early in their race. Often the elite athletes run the second part of a distance faster than the first part $[13,14]$.

\section{Hypothesis}

The following research questions will be investigated in the present study:

a. Will analysing the strategy of the race help coaches and athletes?

b. Do athletes or groups of athletes differ in terms of pace strategy?

\section{Purpose}

The purpose of this research was to study the timeless evolution of walking, as well as the Pacing Strategy Profiles of high-level women in the $20 \mathrm{~km}$ of race walking. The importance of the research was significant as follows: the above information would be able to extend theoretical knowledge, so that the methodology of analysing the data of races, that have been or will be conducted in the future, is applied in practice.

\section{Material and Methods}

\section{Participants}

The practical example of applying the theoretical basis was made during the Women's Greek Championship (Megara 2016), in which 12 athletes of race walking aged 19 to 40 participated $(28.50 \pm 7.20)$. Athletes had experience in endurance training in race walking for at least 5 years $[15,16]$. A prerequisite for their participation in the study was their ability to have reached the qualifying thresholds for the Race Walking National Championships. Which means that these athletes had a high level of training experience and endurance [17]. The race course was certified and measured by SEGAS at $20 \mathrm{~km}$. Took place on the Megara beach on a public road, and consisted of a $2 \mathrm{~km}$ circular route, which athletes were required to walk 10 times.

The present study was a targeted review work with a practical example of applying the theoretical basis.

Independent variables: High-level women athletes in the $20 \mathrm{~km}$ race track, initially divided into 4 groups. The first 3, those who finished $15 \%$ slower than the first, those who finished $15 \%$ - $30 \%$ slower and, finally, those who finished more than $30 \%$ slower than the winner. Then, they are splitted into two groups: those finishing in the top 6 and bottom 6 . Also, the predefined distances of the sections of the route.

Dependent variables: The performance of top-level women athletes in the race of $20 \mathrm{~km}$. The individual times of the athletes in the predetermined sections of the track, as well as their pace strategy.

\section{Research Design}

Initially, the certified distance of the race track (St$20 \mathrm{~km}$ ) divided into 10 sections of $2 \mathrm{~km}$ each was recorded. The same happened with the times (intermediate, final) corresponding to the individual sections $(2 \mathrm{~km})$ of the route. Based on the data of the individual track distances and the respective times of the athletes, the individual pace strategies were found that describe the athletes' tactics in this race.

The appliances that were used to perform the measurements and to evaluate the data were:

a) One video camera (Sony, Full HD 1080, 50 Hz). The camera's resolution was $0.02 \mathrm{~s}$ and it was firmly positioned at the start-stop (where the athletes completed the $2 \mathrm{~km}$ cycle). The video recording of the athletes' passes at $2 \mathrm{~km}$ and recording the electronic timer,

(b) The protocols in which the distances of the race and the kinematic parameters were written.

Statistical Analysis

The analysis included:

1. Descriptive statistics: mean (M), standard deviation (SD) and coefficient of variation (V).

2. Pace strategy analysis for the top 3 athletes, those who finished $15 \%$ slower than the first, those who finished $15 \%$ to $30 \%$ slower than that and, finally, those who finished more than $30 \%$ slower than the winner [18].

3 . Relation of the times (intermediate and final) of the 12 athletes, as well as the first 6 and last 6 athletes, in relation to the distances of the sections of the track.

4. After a detailed explanation of all the terms used for the statistical processing of the work, follows a reference to the $\mathrm{t}$-test. The $\mathrm{t}$ - test method investigates the difference between the mean values of a variable at two time points. In other words, it examines whether the difference of two averages is due to random factors. A prerequisite for the above hypothesis to be valid is that the index $t$ to be greater than or equal to the criterion (tc) value of the t-test. The criterion value is derived from the special t-student price table by selecting any level of significance and any degrees of freedom. In this work the $t$ - test calculations were performed with $5 \%$ statistical significance and two -sided control, with degrees of freedom $\mathrm{N}-1$, where $\mathrm{N}$ is the sample population.

\section{Results}

The following results expand the theoretical knowledge of women's pace strategy in $20 \mathrm{~km}$ of race walking. So that the methodology of analysing the data of races that have been or will be conducted in the future is applied in practice.

Figure 1 shows the time course of the athletes in the predetermined intermediate sections of the $20 \mathrm{~km}$ route of the race, in relation to their ranking. The Table 1 shows the finish times $(\mathrm{t})$ of the leader in each group of athletes of $20 \mathrm{~km}$ of race walking, and their relationship (r) with the distance travelled (s) in individual sections of the route.

For the first athlete (Figure 2) we can see that, there are no significant fluctuations in the intermediate times between her passes. In other words, it is observed that 
she follows Even Pacing Strategy, which concerns the uniform distribution of the expenditure of her forces during the struggle [19].

Table 1. Finish times $(t)$ of the leader in each group of athletes of $20 \mathrm{~km}$ of the race walking and their relation ( $r$ ) with the distance travelled (s) in individual sections of the route.

\begin{tabular}{lll}
\hline Athletes & Time(M) & $\begin{array}{l}\mathbf{r}=\text { distance } \\
(\mathbf{s}) \text { - time (t) }\end{array}$ \\
\hline Winner & 1.29 .35 & $\mathbf{0 , 4 4}$ \\
Group $15 \%$ & 1.37 .14 & $\mathbf{0 , 5 0}$ \\
Group 15 - 30\% & 1.43 .36 & $\mathbf{0 , 4 9}$ \\
Group 30\% & 1.59 .54 & $\mathbf{0 , 4 7}$ \\
Group 100\% (12) & 1.47 .83 & 0,55 \\
\hline
\end{tabular}

In other words, the first winner tried to keep constant the time in the individual passes, throughout the race, in order to run at the same pace.
The athletes, who finished in times up to $15 \%$ slower than the 1st winner (Figure 3), had fluctuations in the intensity of their effort or rhythm during the race. In the team that finished in times up to $15-30 \%$ slower than the 1st winner (Figure 4) you can see that the fatigue comes much faster than in the previous group. In other words, their intermediate times, along the route, vary from passage to passage, either increasing or decreasing significantly. These athletes display Variable Pacing Strategy $[19,7]$.

As for the athletes who finished in times over $30 \%$ slower than the first winner (Figure 5), their common tactics are obvious up to the 14th kilometre. But from then on, with the effect of fatigue, we notice a big difference in times of this group in the last kilometres. The athletes don't seem to have used a specific pace strategy; they just tried to keep a steady pace all the way, which they didn't manage. The difference in capacity between this group and the previous ones is obvious. Since we are talking about athletes who finished in the last positions of the race

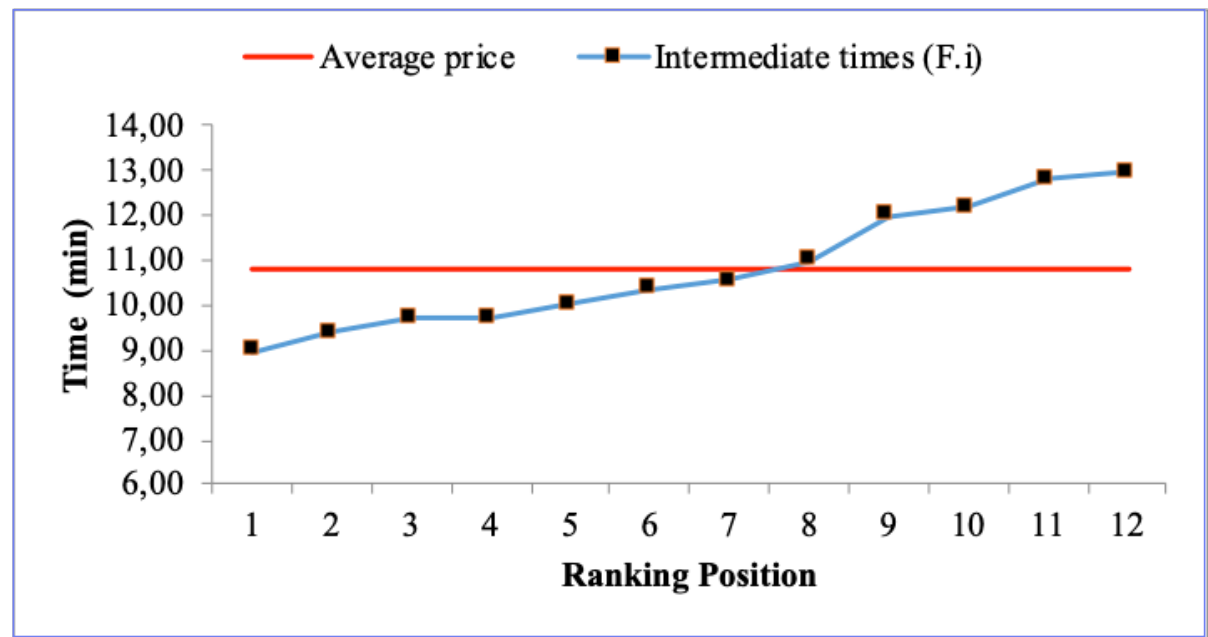

Figure 1. An intermediate time in the respective sections (F.i) of women's $20 \mathrm{~km}$ of race walking in relation to their classification position.

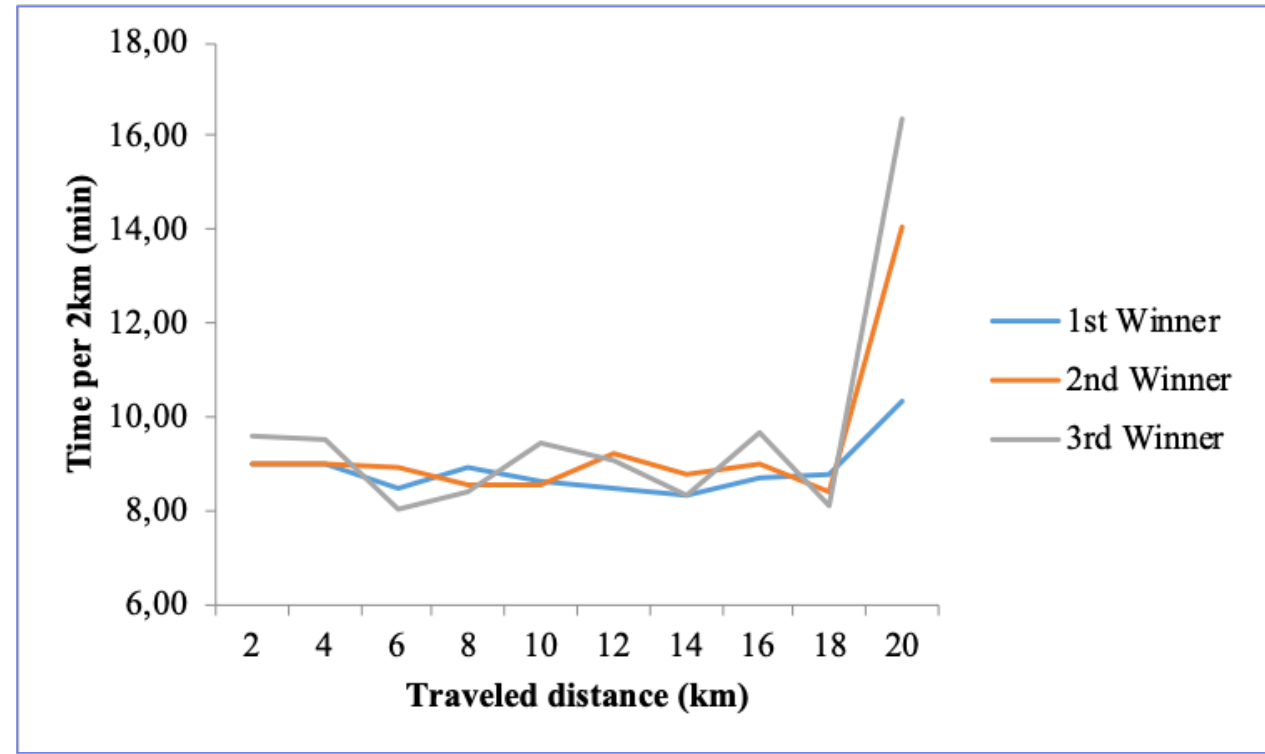

Figure 2. The individual times per $2 \mathrm{~km}$ of the winners in the $20 \mathrm{~km}$ women's race walking. 


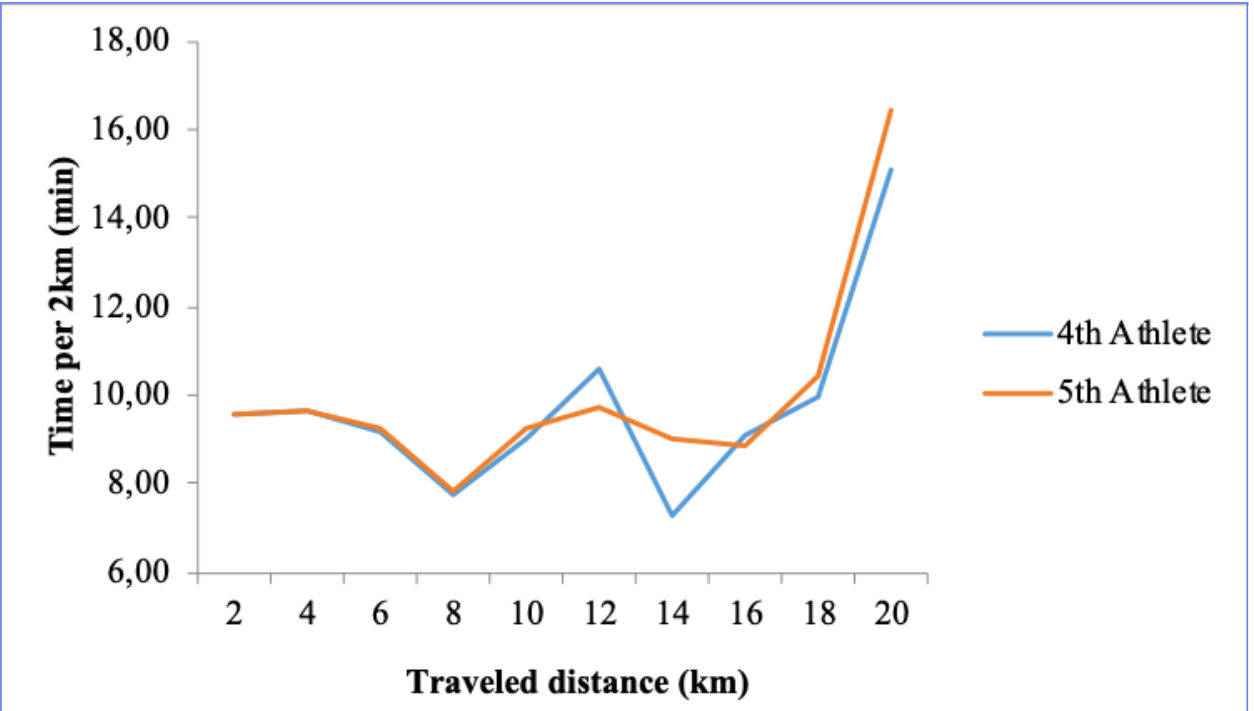

Figure 3. The individual times per $2 \mathrm{~km}$ of the group $<15 \%$ of the athletes in the $20 \mathrm{~km}$ of race walking

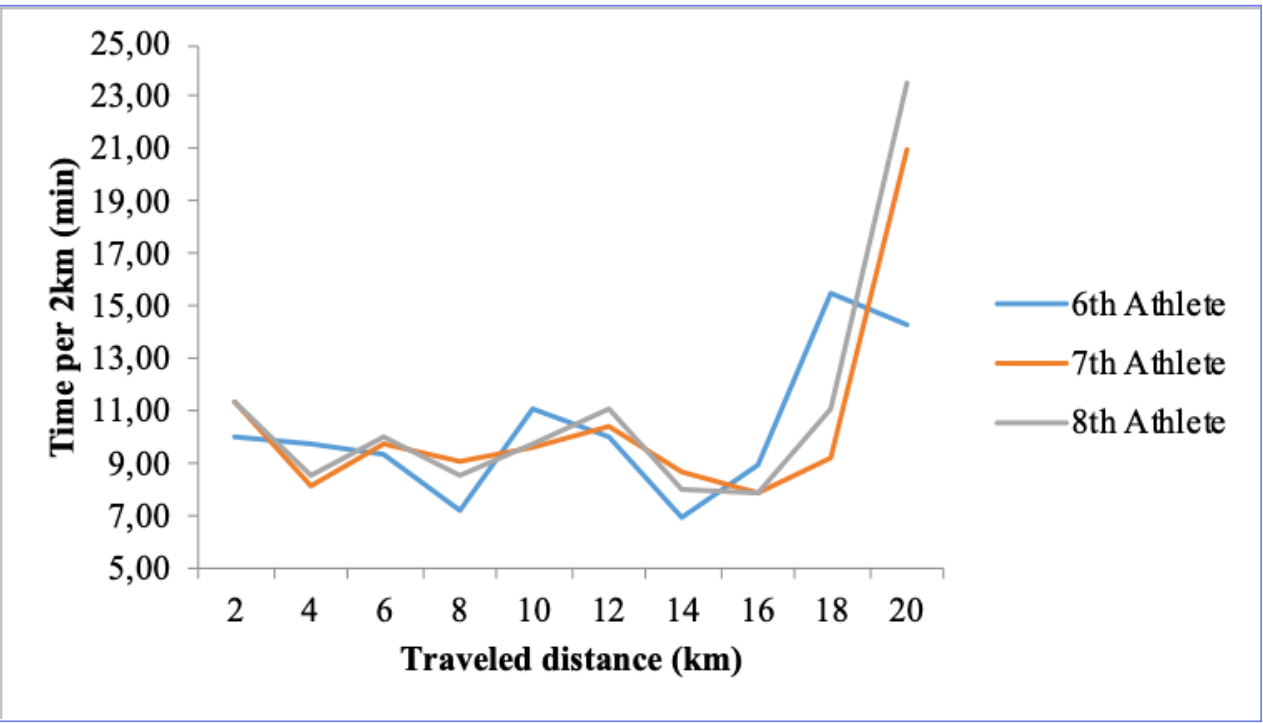

Figure 4. The individual times per $2 \mathrm{~km}$ of the group $15-30 \%$, of the athletes in the $20 \mathrm{~km}$ of race walking.

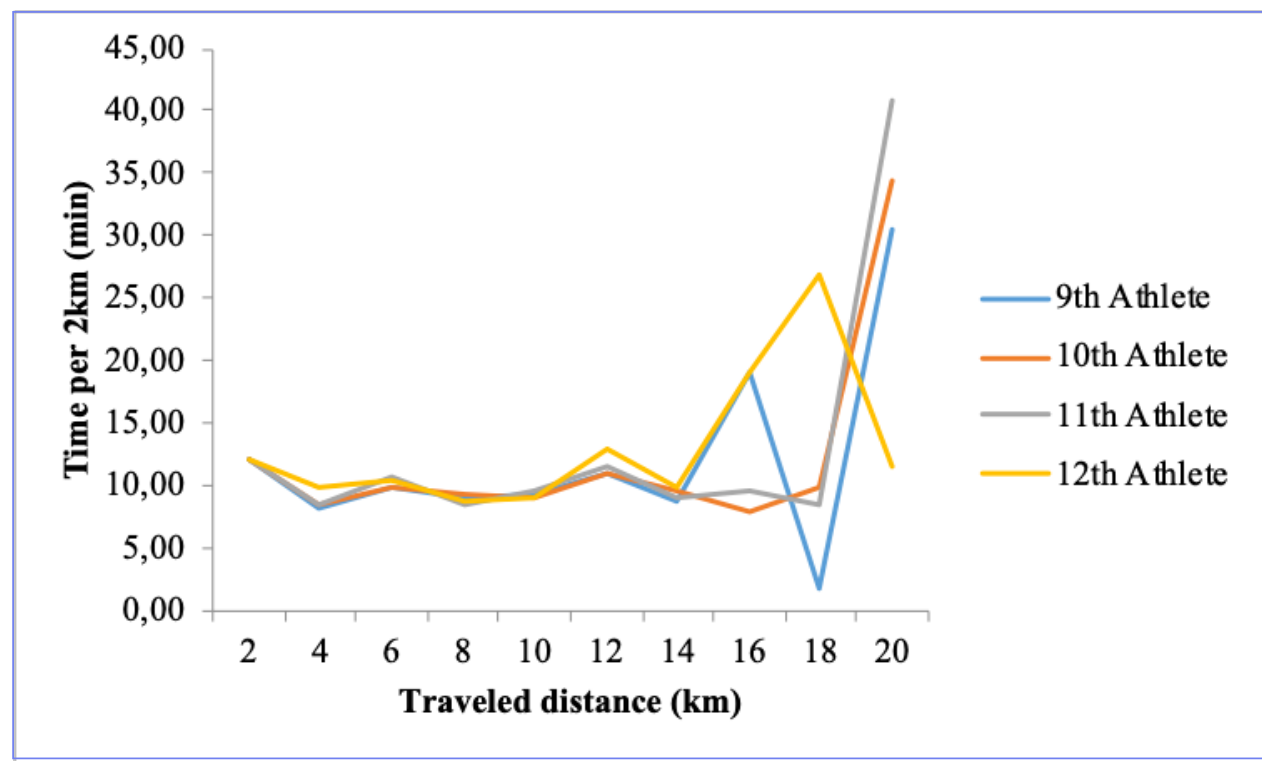

Figure 5. The individual times per $2 \mathrm{~km}$ of the group $>30 \%$ of the athletes in the $20 \mathrm{~km}$ of race walking. 
(Figure 6), and that was the reason that the fatigue came earlier than the previous groups [19].

Correlation coefficients (r) in relation to the performance of the women's teams were significant (Table 2). The t-test between the team of the first 6 athletes M1-6 (9.69 $\pm 0.48 \mathrm{~min})$ and that of 6 last athletes M7-12 (11.92 $\pm 0.97 \mathrm{~min})$, with a correlation $\mathrm{r}=0.97$. Showed the difference in performance between the two groups of athletes (Figure 7) $\mathrm{t}=6,255>\mathrm{tc}=2,179$ with bilateral control $(\mathrm{p}<0.05)$. It was found that none of the

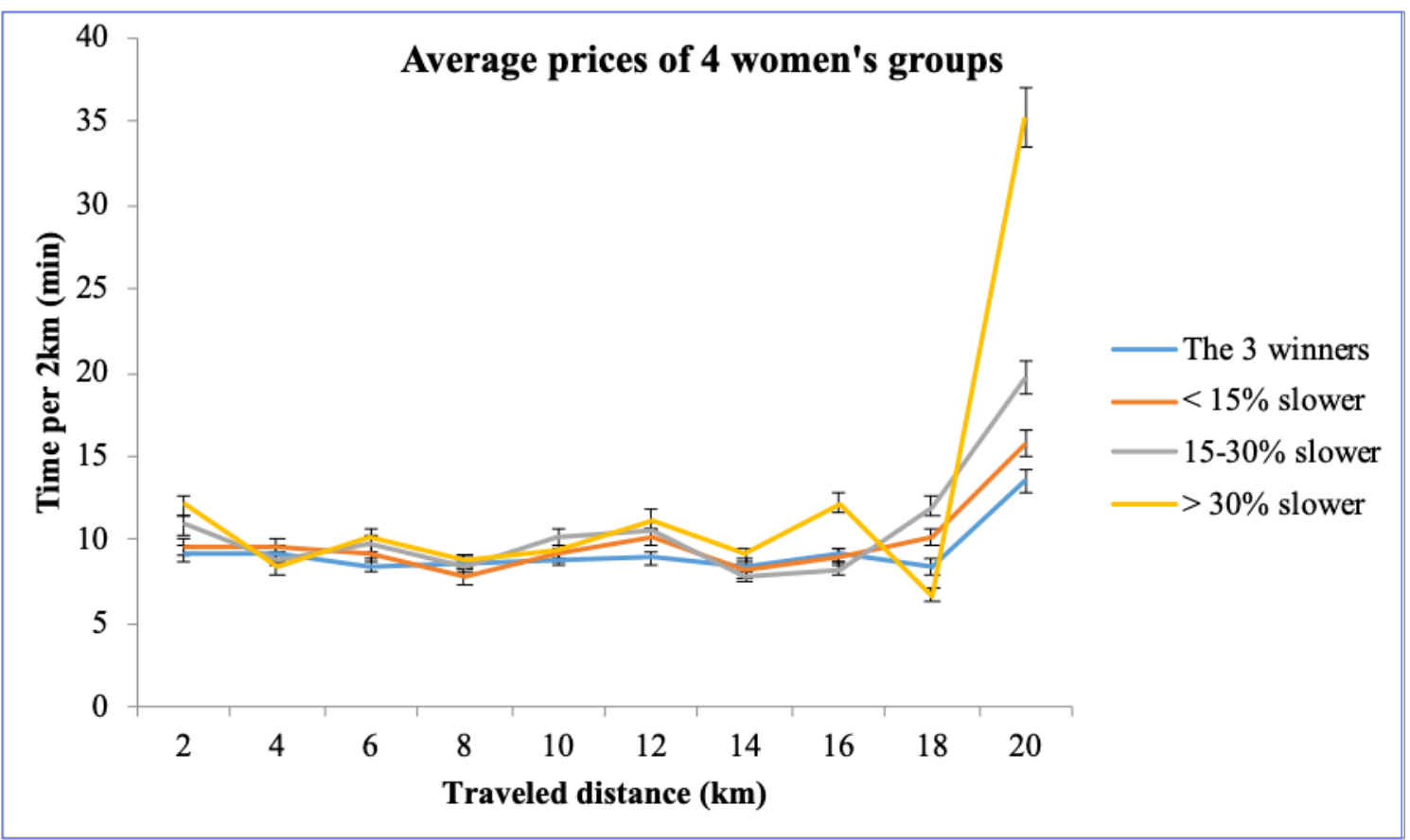

Figure 6. The individual times per $2 \mathrm{~km}$ of the four groups in the $20 \mathrm{~km}$ women's race walking.

Table 2. The correlation coefficients $(r)$ in relation to the performance of the groups of walkers.

\begin{tabular}{llllll}
\hline $\mathbf{r}$ & The 3 winners & $<\mathbf{1 5 \%}$ slower & $\mathbf{1 5 - 3 0 \%}$ slower & $\mathbf{> 3 0 \%}$ slower & $\mathbf{1 2}$ athletes \\
\hline The 3 winners & $\mathrm{X}$ & 0,94 & 0,90 & 0,98 & 0,95 \\
< 15\% slower & & $\mathrm{X}$ & 0,97 & 0,92 & 0,98 \\
15-30\% slower & & $\mathrm{X}$ & 0,89 & 0,98 \\
> 30\% slower & & & $\mathrm{X}$ & 0,95 \\
12 athletes & & & & $\mathrm{X}$ \\
\hline
\end{tabular}

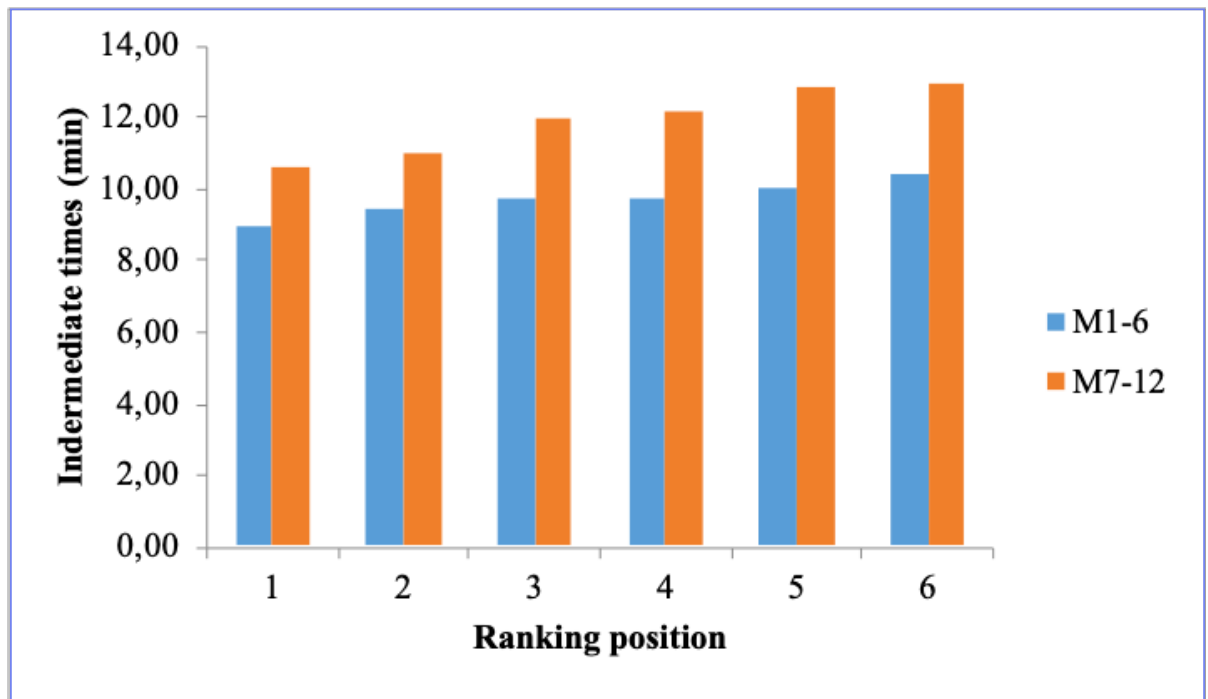

Figure 7. Comparison of the mean values (M) of the performance between the group of the first 6 athletes M1- 6 $(9.69 \pm 0.48)$ and the last 6 athletes M7-12 (11.92 \pm 0.97$)$, with correlation $r=0.97$ where the t-test showed the difference in performance between the two groups of athletes $t=6.25>t c=2,179$ with bilateral control $(p<0.05)$. 
athletes who belonged to the first group, who were the winners, started the race faster than their personal record. The athletes of the last group started the race faster than their own performance [19].

The fact that a large percentage of athletes that did not finish in the first places, start faster than the ones that followed. Leads us to the conclusion that, these athletes started the race seduced by how relaxed they felt at that moment, not having the perception of impending fatigue.

\section{Discussion}

As we can observe by studying the profiles of the pace strategy at $20 \mathrm{~km}$ of race walking in the practical example of application of the theoretical basis, there are differences from athlete to athlete. The winners (the first three athletes) seem to follow the Even Pacing Strategy, which deals with the uniform distribution of the cost expenditure of their forces during the race. In other words, these athletes tried to maintain a constant passage time, in each circular route of $2 \mathrm{~km}$ and a small difference of their individual speeds between their passes [19]. The lower this deviation, the better the performance of the athletes. Leads us to the conclusion that, the optimal tactic at this distance is the constant passes of the athletes at a speed equal to the average speed.

After all, the tactics of walking, like all long-distance roads, must be accompanied by specialized technique and speed distribution [19]. These findings are in line with previous studies that have analysed the path of athletes in the marathon. They found that the change in speed was less for the best runners compared to the slower athletes $[20,19]$. Athletes, who finished up to $30 \%$ slower than the winner, show Variable Pacing Strategy. These athletes had greater fluctuations in the intensity of their effort, or rhythm, during the race. The pace strategy in race walking, as in all long-distance roads, must be accompanied by the specialized technique [19]. It was found that, the optimal deviation of the speed from the average speed improves the final performance of the athletes, which was expected according to previous studies conducted in this subject $[8,9]$.

\section{Conclusions}

With the help of this study, we obtained the following important information: that the winners of the race used Even Pace Strategy, maintaining a constant speed for most of the route at the $20 \mathrm{~km}$ of race walking. We also concluded that, the groups of athletes tested differ from each other in terms of pace strategy. As the level of the athletes decreases, the Variable Pace Strategy was used, while the athletes, who finished in the last positions, do not seem to have managed to maintain any particular pace strategy.

It is therefore recommended that athletes should design with their coaches the model of the pace strategy they wish to follow. Not be carried away by the momentary latent sense of relaxation, they have at the beginning of the race. The application by the coaches of the relevant training protocols to their athletes, will significantly contribute to the improvement of their final performance.

\section{Conflict of interest}

Authors declare no conflict of interest.

\section{References}

1. Benakis A. The technique of racing walking. [dissertation]. School of Physical Education and Sports Science, National and Kapodistrian University of Athens; 1988. (in Greek)

2. Stavrakakis N, Albanidis E. The therapeutic use of sport during the byzantine period. Archives of Hellenic Medicine, 2015; 32(1):96-101 (in Greek)

3. Mannell R, Reid D. Work and leisure. In: Leisure Studies, Prospects for the Twenty-first century, 1999. P. 151-163.

4. Sylvester C. The western idea of work and leisure: traditions, transformations and the future. In: Leisure Studies, Prospects for the Twenty-first century; 1999. P. 17-31.

5. Giovanis V. Skiing technique. Athens: Elvekalt Publications; 2006 (in Greek)

6. Panou HA, Giovanis VF. Review on interventional "nordic walking" exercise programs for improving life quality for older adults. Journal of Educational Research and Studies, 2016; 4 (3): 26-29.

7. Abbiss CR, Laursen PB. Describing and understanding pacing strategies during athletic competition. Journal of Sports Medicine, 2008; 38(3): 239-252. https://doi.org/10.2165/00007256-200838030-00004

8. Foster C, Snyder A, Thompson NN, Green MA, Foley M, Schrager M. Effect of pacing strategy on cycle time trial performance. Medicine and Science in Sports and Exercise, 1993; 25(3): 383-388. https://doi.org/10.1249/00005768-199303000-00014
9. Foster C, Hettinga F, Lampen J, Dodge C, Bobbert M, Porcari J. Effect of competitive distance on energy expenditure during simulated competition. International Journal of Sports Medicine, 2004; 25 (3): 198-204.

10.Thompson KG. Pacing: Individual strategies for optimal performance. Human Kinetics; 2014.

11.Aschenbrenner P, Erdmann WS, Giovanis V, Lipinska P. Investigations on technique and tactics of race walking during Olympic Games Athens 2004 - first announcement. University of Salzburg; 2006.

12.Ruchlewicz,T, Staszkiewicz R, Chwala W, Laska J. Biomechanical parameters of race walking on the example of tests of an international champion class walkers. In: Urbanik $\mathrm{Cz}$ (ed.). Zagadnienia biomechaniki sportu-technika ruchu [Biomechanics of sport issues - movement technique]. Warsaw; 2003. P.46-57 (in Polish)

13.Erdmann WS, Giovanis V. Investigations on kinematics of giant slalom's tactics in alpine skiing. In: Miyashita M., Fukunaga T. (ed.) Proceedings, XVI Congress of the International Society of Biomechanics, Tokyo: University of Tokyo; 1997. P. 79.

14.Lipińska P. Wielkości kinematyczne i geometria trasy a taktyka biegu w maratonie [Kinematic quantities and route geometry and tactics of running a marathon]. [dissertation]. Gdańsk: AWFiS; 2006 (in Polish)

15.Hanley B, Bissas A, Drake A. Biomechanical analysis of elite race walkers. Technique analysis and the effects of 
fatigue. New Studies in Athletics, 2008; 23(4): 17-25.

16.Radovanovic D. Specific alterations of physiological parameters in competitive race walkers. Aplied Physiology, 2011; 98 (4): 449-455. https://doi.org/10.1556/APhysiol.98.2011.4.8

17.Chwala W. Influence of space-time quantities on the oscillations of the total body mass center (BMC) as a function of the increasing speed of sports walk in the group of master class walkers. In: Urbanik Cz, Mastalerz A. (ed). Biomechanika sportu $i$ rechabilitacji [Biomechanics of sport and rehabilitation]. Warsaw; AWF; 2009. P. 29-43. (in Polish)
18.Hanley B. An analysis of pacing profiles of worldclass racewalkers. International Journal of Sports Physiology and Performance, 2013; 8(4), 435-441. https://doi.org/10.1123/ijspp.8.4.435

19.Hanley B, Stellingwerff T, Hettinga FJ. Successful Pacing Profiles of Olympic and IAAF World Championship Middle-Distance Runners Across Qualifying Rounds and Finals. International Journal of Sports Physiology and Performance 2019;14:894-901. https://doi.org/10.1123/ijspp.2018-0742

20.Giovanis V, Erdmann WS. Kinematic Analysis of Runners in the 2011 Olympus Marathon. Research Journal of Physical Education Sciences, 2013; 1(1): 7-12.

\section{Information about the authors:}

Vasilios Giovanis; (Corresponding Author); Ph.D.; http://orcid.org/0000-0003-2511-8286; vgiovan@phed.uoa.gr; School of Physical Education and Sport Science, National and Kapodistrian University of Athens; 41 Ethnikis Antistassis Str., Daphne 17237, Athens, Greece.

Panagiota Fitili; Msc ; https://orcid.org/0000-0001-5682-3047; fytili@hotmail.com; School of Physical Education and Sport Science, National and Kapodistrian University of Athens; 41 Ethnikis Antistassis Str., Daphne 17237, Athens, Greece.

Cite this article as:

Fitili P, Giovanis V. Timeless evolution of walking and pace strategy of women's race walking. Pedagogy of Physical Culture and Sports, 2020;24(6):278-284.

https://doi.org/10.15561/26649837.2020.0601

This is an Open Access article distributed under the terms of the Creative Commons Attribution License, which permits unrestricted use, distribution, and reproduction in any medium, provided the original work is properly cited (http://creativecommons.org/licenses/by/4.0/deed.en).

Received: 01.05.2020

Accepted: 12.06.2020; Published: 30.12.2020 